\title{
Author Correction: Long range electronic phase separation in $\mathrm{CaFe}_{3} \mathrm{O}_{5}$
}

\author{
Ka.H. Hong (1) ${ }^{1}$, Angel M. Arevalo-Lopez ${ }^{2}$, James Cumby (D) ${ }^{1}$, Clemens Ritter $^{3} \&$ J. Paul Attfield (1D) ${ }^{1}$
}

Correction to: Nature Communications https://doi.org/10.1038/s41467-018-05363-6; published online 30 July 2018

The original version of this Article contained an error in the third sentence of the legend of Fig. 2, which incorrectly read 'The phase fractions of the charge ordered (CO) phase, obtained from synchrotron (X) and neutron (N) diffraction data are shown in the righthand panel.' The correct version states 'charge averaged (CA)' in place of 'charge ordered (CO)'. This has been corrected in both the PDF and HTML versions of the Article.

Published online: 28 August 2018

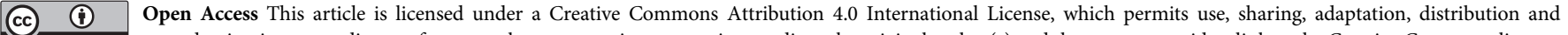
and indicate if changes were made. The images or other third party material in this article are included in the article's Creative Commons license, unless indicated otherwise in a credit

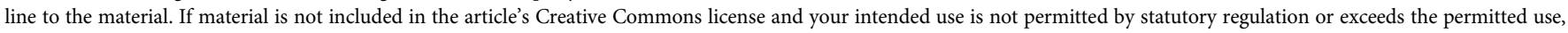
you will need to obtain permission directly from the copyright holder. To view a copy of this license, visit http://creativecommons.org/licenses/by/4.0/.

(C) The Author(s) 2018

\footnotetext{
${ }^{1}$ Centre for Science at Extreme Conditions and School of Chemistry, University of Edinburgh, Mayfield Road, Edinburgh EH9 3JZ, UK. ${ }^{2}$ Univ. Lille, CNRS, Centrale Lille, ENSCL, Univ. Artois, UMR 8181 - UCCS - Unité de Catalyse et Chimie du Solide, Lille F-59000, France. ${ }^{3}$ Institut Laue-Langevin, 71 avenue des Martyrs, Grenoble 38000, France. Correspondence and requests for materials should be addressed to J.P.A. (email: j.p.attfield@ed.ac.uk)
} 